\title{
Проблемы формирования кадрового резерва муниципальных служащих
}

\author{
Е. Н. Фурман ${ }^{1}$ Н. П. Молчанова ${ }^{2 凶}$ \\ ${ }^{1}$ Курская академия государственной и муниципальной службы, Интернациональная ул., 6-Б, \\ Станционная улица, 9, 305044, Курск, Курская область, Российская Федерация
}

2 Финансовый университет при Правительстве Российской Федерации, Ленинградский проспект, д. 49, 125993, Москва, ГСП-3, Российская Федерация

Для цитирования: Фурман Л. В., Молчанова Н. П. Проблемы формирования кадрового резерва муниципальных служащих // Вестник Воронежского государственного университета. Серия: Экономика и управление. 2020. № 3. С. 89-100. DOI: 10.17308/econ.2020.3/3108

\begin{abstract}
Предмет. Задачи, разрабатываемые в рамках проводимой внутрирегиональной политики, весьма разнообразны и направлены на улучшение жизнедеятельности населения и развитие муниципальных образований. Успешность их реализации во многом зависит от количественных и качественных характеристик располагаемых факторов производства. Ключевая роль принадлежит кадровому потенциалу, а именно наличию контингента муниципальных служащих, обладающих необходимыми компетенциями и уровнем квалификации. В связи с этим необходима подготовка инструментария для ранжирования качества трудовой деятельности муниципальных служащих, адекватного специфическим условиям пространственного развития. Методика оценки трудового вклада должна включать стимулы для повышения результативности управленческой деятельности, соответствующие требованиям современного периода формирования информационной экономики.

Цель. Выявление взаимосвязи между квалификацией и компетенциями работающих специалистов в администрациях муниципальных образований и социально-экономическими результатами функционирования периферийных территорий субъектов Российской Федерации.

Методология. В процессе исследования применялись методы индукции и дедукции, сравнительного и ситуационного анализа, экспертных оценок, статистические методы обработки и анализа информации, результаты социологических опросов.

Результаты. Выполнен анализ работы муниципальных администраций на основе материалов исследований по Центральному федеральному округу и Курской области с применением официальной статистической информации и материалов социологических наблюдений. Установлены факторы, положительно и отрицательно влияющие на результативность деятельности органов местного самоуправления. Изучены особенности работы и подбора муниципальных служащих, выявлены существенные недостатки в их обучении и подготовке к практической деятельности. Обсуждение результатов. Актуальным является вопрос о создании качественно новой системы подготовки муниципальных служащих, обладающих знаниями и компетенциями, востребованными для работы в условиях цифровизации. Необходимо активно применять различные формы обучения и повышения квалификации специалистов местных администраций, учитывать мнения жителей городских и сельских поселений. Инструменты программно-целевого подхода и экспертных оценок целесообразно рекомендовать к использованию при обосновании масштабов подготовки контингента резервистов для пополнения кадров муниципальных служащих.

Выводы. Эффективность деятельности публичных органов власти низового уровня во многом определяется активной позицией глав муниципальных районов и работников аппарата муниципалитетов. Создание кадрового резерва муниципальных служащих оказывает позитивное влияние на результаты работы администраций муниципальных образований и социально-экономическое положение территорий. Для достижения целевых ориентиров по уровню запланированных темпов развития экономики и социальной сферы необходимо активизировать различные формы работы с кадрами специалистов администраций городских и сельских поселений. Сформулированы рекомендации по формированию резерва муниципальных служащих, основанные на применении социальных технологий и моделировании компетенций с целью качественной подготовки специалистов для работы на руководящих должностях в местных органах власти.
\end{abstract}

Ключевые слова: внутрирегиональная политика, местное самоуправление, особенности муниципальной экономики, финансовые ресурсы муниципалитетов.

(C) Фурман Е. Н., Молчанова Н. П., 2020

Вестник ВГУ. Серия: Экономика и управление. 2020. № 3. С. 89-100. 


\section{Введение}

Необходимость ускорения темпов экономического развития подчеркнута Президентом Российской Федерации ${ }^{1}$, и для решения данной задачи высокой государственной важности предстоит осуществить целый комплекс мер, успешная реализация которых складывается под влиянием различных факторов. Основной ячейкой территориального управления являются муниципальные образования. Они выполняют функцию регулирования хозяйственных отношений на территории, находящейся в их ведении и выступают в качестве полноправного субъекта этих отношений, способного самостоятельно расширять свой экономический потенциал. Доктор экономических наук Е. Б. Дворядкина и исследователь Е. А. Белоусова справедливо полагают, что «муниципальное хозяйство во многом есть результат действий органов местного самоуправления, которые должны быть направлены на удовлетворение коллективных потребностей местного сообщества» [6, с. 45]. Задачи повышения конкурентоспособности и инвестиционной привлекательности территорий могут решаться только в контексте поиска организационных и экономических инструментов повышения эффективности муниципальной экономики.

Сложные вопросы социально-экономического развития (в увязке регионального и муниципального уровней) широко обсуждаются в работах ученых-регионоведов. Доктор экономических наук Т. В. Ускова предметно рассматривает проблемы развития муниципальных образований. При наличии весомого потенциала сельских территорий эффективность его использования остается на низком уровне. «Сформировался ряд проблем и негативных тенденций в социально-экономическом развитии сельских территорий, снижающих уровень и качество жизни селян» $[14 ; 15]$. В их числе обращается внимание на нехватку высококвалифицированных кадров, «высокий уровень дифференциации в социально-экономическом развитии сельских территорий, неразвитость социальной и инженерной инфраструктуры на селе» $[14$, с. 1]. Позитивные изменения в пространственном развитии увязываются с перспективами совершенствования региональной политики, целенаправленной работой публичных органов власти по расширению спектра

1 Указ Президента Российской Федерации от 21 июля 2020 г. № 474 «О национальных целях развития Российской Федерации на период до 2030 года». URL: http:// publication.pravo.gov.ru/Document/View/0001202007210012 применяемых методов управления социально-экономическими процессами, активизацией предпринимательского сектора и местного сообщества в деятельности по стабилизации положения сельских территорий.

Доктор экономических наук Е. М. Бухвальд и кандидат экономических наук Н. В. Ворошилов при исследовании вопросов развития муниципальных образований и института местного самоуправления установили основные проблемы, сдерживающие эффективное управление развитием муниципалитетов: «несовершенство законодательства, регламентирующего развитие местного самоуправления; дефицит собственных доходных источников и недостаточность финансовой поддержки со стороны государства; низкая эффективность взаимодействия с органами государственной власти; отсутствие полной и достоверной информации о социально-экономическом развитии муниципалитета; пассивность местного населения; ограниченность полномочий органов местного самоуправления в сфере экономического развития территорий [3, с. 133]. Анализируя сложившуюся ситуацию, исследователи отмечают негативное влияние дефицита квалифицированных кадров в органах местного самоуправления. Именно на данную причину указали при проведении опроса в Вологодской области $69 \%$ руководителей муниципальных районов, 79 \% - городских поселений и 46 \% сельских. С чем же связаны кадровые проблемы? В первую очередь - с уровнем оплаты труда в органах местного самоуправления. По данным Росстата, ее уровень на 20-23 \% традиционно ниже средней заработной платы по экономике страны [там же, с. 138].

Однако есть и другие причины. В их числе количественные и качественные характеристики трудового потенциала. Переход к цифровым платформам инициирует активизацию деятельности кадровых служб предприятий и организаций во всех отраслях региональной экономики. Результаты работы органов региональной власти и местного самоуправления напрямую зависят от компетентности и квалификации государственных и муниципальных служащих. В круг прогрессивных форм работы с управленческим персоналом входит создание резерва кадров для администраций муниципальных образований. В деятельности органов исполнительной власти вопросы подготовки муниципальных служащих и определения потребностей в специалистах обладают высокой актуальностью. Предметно обосновать объем 
и структуру формируемого резерва управленческих кадров можно только на основе анализа статистических данных, результатов социологических обследований, хода реализации государственной политики регионального развития и текущей кадровой политики. Ключевым звеном работы муниципальных служб становится совершенствование подходов к формированию контингента резервистов, обновлению применяемых социальных технологий и моделированию компетенций.

\section{Методы исследования}

Актуальность применения пространственного подхода для исследования тенденций социально-экономического развития объясняется обширностью сельских территорий на экономической карте России. Необходимость выравнивания условий жизнедеятельности населения по всей стране выдвигает следующие стратегические задачи, на которые указывают доктора экономических наук И. Н. Молчанов и Н. П. Молчанова: «поддержка различных видов экономической деятельности, характерных для сельской местности; развитие на располагаемой ресурсной базе производственных предприятий и организаций сферы услуг; укрепление внутри- и межселенных связей, расширение полномочий органов местного самоуправления; сохранение и приумножение всех компонентов этнокультурного и природно-ресурсного потенциалов» [10, с. 80]. Решение задач подобной масштабности возможно только на основе инновационных принципов, методов и инструментов управления. Например, применение форсайт-технологий как современного инструмента оптимизации системы регионального менеджмента. Их высокая эффективность на мезоуровне и накопленный опыт применения описывается в работе российских исследователей [24]. На основе долгосрочного прогноза и региональных программных документов, а также SWOT-анализа социально-эколого-экономической системы Республики Татарстан выполнены рекомендации по применению форсайт-технологий для поддержания высоких темпов экономического роста, обосновывается ведущая роль муниципальных образований и местного самоуправления в обеспечении устойчивого развития данной территории.

В двухуровневой системе местного самоуправления ключевая роль отводится органам власти муниципальных районов. Именно они выполняют функции координаторов работ, связанных с решением вопросов местного и межпоселенческого уровня. Пространственная организация экономики нашей страны трансформируется под влиянием происходящих изменений в размещении производительных сил, условий международной торговли и научно-технического развития ${ }^{2}$. В связи с этим чрезвычайно важной задачей является методологическое обеспечение функционирования всех административно-территориальных образований. В основе сбалансированного территориального управления лежит системный подход, базирующийся на следующих разновидностях экономической политики: 1) государственной региональной экономической политике, которая регламентирует деятельность регионов - субъектов Российской Федерации и 2) политике, получившей название «внутрирегиональной», которая конкретизирует вышестоящую политику применительно к муниципальным образованиям.

Согласованное воплощение в жизнь названных разновидностей экономической политики обеспечить достаточно непросто, что отчасти можно объяснить особенностями административно-территориального деления страны ${ }^{3}$. Сложность государственной политики регионального развития раскрывается в Указе Президента Российской Федерации, а ее содержание состоит в проведении стимулирующих мер поддержки административно-территориальных образований, обязательным условием которой является самостоятельное осуществление ими функций и полномочий, установленных Конституцией и федеральными законами. В этом случае обеспечивается дифференцированный подход к решению накопившихся проблем в зависимости от географического расположения, экономических и социальных интересов и особенностей территорий ${ }^{4}$.

Происходящие в экономической сфере изменения закономерно распространяются на

${ }^{2}$ Стратегия пространственного развития Российской Федерации на период до 2025 г. Минэкономразвития, 2018.114 c. URL: http:// http://static.government.ru/media/ files/UVAlqUtT08o60RktoOX122JjAe7irNxc.pdf

${ }^{3}$ На территории Российской Федерации функционируют 85 субъектов, 21501 муниципальное образование, в том числе 1731 муниципальный район, 611 городских округов, 3 городских округа с внутригородским делением.

${ }^{4}$ Основы государственной политики регионального развития Российской Федерации на период до 2025 г. Утверждены Указом Президента Российской Федерации от 16 января 2017 года № 13. URL: http://kremlin.ru/acts/ bank/41641 
систему социально-трудовых отношений и затрагивают качественные характеристики работников. Дискутируются вопросы о том, как именно ужесточаются требования к качеству трудового потенциала в целом, каким образом перераспределяются по своей значимости его отдельные компоненты? На основе данных государственной статистики можно рассмотреть различные аспекты состояния рынка труда, но для анализа востребованных работодателями приобретенных претендентами навыков: технологических (программирование, компьютерная грамотность), высоких когнитивных (креативность, комплексная обработка информации и ее интерпретация), социальных и эмоциональных (лидерство и управление, предпринимательство и инициативность), нужны специальные научные исследования, полагает кандидат экономических наук А. В. Попов [11]. Подобные исследования проводились и зарубежными учеными. Например, Д. Отором, Ф. Леви и Р. Мюрнейном было установлено, что во второй половине XX в. значимость рутинного когнитивного и ручного труда в американской экономике заметно сократилась, в то время как умения решать неструктурированные проблемы и работать с новой информацией приобрели особую актуальность [20]. К схожим выводам пришла группа ученых, проанализировавших ситуацию с навыками в 30 странах с различным уровнем экономического развития: с ростом дохода на душу населения происходит снижение интенсивности ручных навыков и увеличение нестандартных когнитивных и межличностных [19].

Круг целей и задач, которые призвана решать государственная политика регионального развития, весьма широк и находит отражение в научных публикациях отечественных ученых [4; 7; 12; 16]. Их изучение приводит к выводу о разнообразии и неординарности возникающих на разныхуровнях государственного и муниципального управления проблем, для решения которых требуются высокопрофессиональные кадры государственных и муниципальных служащих. Кандидат экономических наук Н. В. Ворошилов описывает специфику проведения «внутрирегиональной» политики, согласно которой деятельность региональных органов власти должна состоять не только в определении, но и в «реализации целей и приоритетов территориального развития, механизма стимулирования, поддержки и содействия развитию муниципальных образований в целях обеспечения комплексного и устойчивого развития региона» [8, с. 61].
В ряде работ, сконцентрированных на вопросах исследования трудового потенциала, раскрываются существующие взаимосвязи между результатами деятельности органов муниципального управления и кадровым составом муниципальных служащих. Повышенное внимание к качеству подготовки квалифицированных специалистов для работы в администрациях муниципальных образований инициирует целесообразность применения новых технологий. Особую актуальность приобретает вопрос формирования кадрового резерва. Цель этой деятельности состоит в подготовке компетентных профессиональных кадров. На предварительном этапе необходимо обеспечить отбор претендентов, способных в будущем, после соответствующем обучении, на высоком профессиональном уровне выполнять функции муниципальных служащих.

\section{Обсуждение результатов}

Внимание, которое уделяется вопросам подготовки квалифицированных специалистов для работы в администрациях публично-правовых образований, связано со многими причинам. Прежде всего муниципальные служащие должны уметь творчески применять в своей деятельности философские и теоретические экономические концепции, использовать современные компьютерные технологии, уметь работать с нормативными и другими официальными документами, экономической и финансовой информацией. Сложность практической работы по управлению финансами отдельных территорий подчеркивает французский экономист и публицист Э. Клеман-Питио: «В России нет единой модели финансирования всех регионов....Чтобы обеспечить рост масштабов и эффективность региональных экономик, бюджетные трансферты должны согласовываться со стратегиями обустройства территорий» [9, с. 19-20]. Мысль о жизнеспособности системы жизнеобеспечения подчеркивается философом-прагматиком Д. Дьюи: он называет «социально организованным интеллектом» систему муниципального управления, в которой динамичный рост богатства построен на основе местных человеческих и материальных ресурсов, если она взаимоувязана со стратегией обустройства территорий [22].

В условиях макроэкономической неопределенности проявляются различного рода риски, в том числе и финансовые. На особенности возникновения финансовых рисков на уровне 
публично-правовых образований, которые обусловлены проводимой финансовой политикой и возникают в процессе финансовой деятельности, указывает доктор экономических наук Н. М. Сабитова: «Возможности реализации финансовой политики... для Российской Федерации и для субъектов РФ, и тем более для муниципальных образований различны, поскольку доступ к использованию фискальных и монетарных инструментов различен. Поэтому финансовые риски имеют разную степень влияния и на финансовую деятельность публично-правовых образований» $[13$, с. 567]. Особенности финансовой деятельности государства, которые обусловлены, с одной стороны, формированием средств (доходов и накоплений) экономических субъектов, а с другой - их расходованием, - оказывают влияние на возникновение финансовых рисков. Представляется важным понимание работниками местных администраций особенностей участия государства в финансовой деятельности на муниципальном уровне управления и связанных с этим рисковых ситуаций.

Общепринятое деление рисков на систематические (влияющие в равной мере на деятельность всех экономических субъектов) и несистематические (обусловленные качеством менеджмента) позволяет предметно их классифицировать. Вследствие принятой практики бюджетного процесса оба названные вида рисков возникают на различных уровнях бюджетной системы, поскольку перераспределение финансовых ресурсов между регионами и муниципальными образованиями происходит преимущественно в форме межбюджетных трансфертов, при планировании и использовании бюджетных средств. Применительно к деятельности публично-правовых образований муниципального уровня несистематические риски в большей мере проявляются при формировании и исполнении местных бюджетов. В связи с этим одной из задач управления муниципальными финансами является минимизация несистематических рисков.

Чем же обусловлена необходимость создания резерва кадров муниципальных служащих? Данная деятельность имеет высокую общественную значимость и осуществляется в целях подъема на качественно новый уровень гражданской службы и раскрытия потенциала наиболее перспективных и талантливых руководителей. Кандидатом экономических наук И. А. Ашмаровым обобщены отдельные основополагающие принципы, на которых строится обучение государственных и муниципальных служащих [1, с. 6]. Из представленных в тексте статьи формулировок следует необходимость соблюдения принципа «образование в течение всей жизни», преодоление тенденций текучести кадров, применение гибких систем материального и морального стимулирования специалистов, понимание обучающимися общественной значимости выбранной профессии.

В процессе проведения исследований учеными выявляются как позитивные, так и негативные практики работы муниципальных служащих в российских регионах. Интерес вызывает накопленный положительный опыт в целях его повсеместного распространения для применения в работе органов местного самоуправления. Например, ученые С. А. Воронцов и А. В. Понеделков провели социологическое исследование муниципальных территорий целого ряда субъектов Российской Федерации, хорошо укомплектованных персоналом и эффективно работающих. Была выполнена оценка эффективности внутрирегиональной экономической политики и обеспечения администраций муниципальных образований квалифицированными кадрами управленческого персонала, т. е. эффективным менеджментом. Это позволило установить, что причины, препятствующие росту инвестиционной привлекательности и конкурентоспособности территорий, частично связаны с особенностями ротации кадров в местных органах управления и муниципальных образованиях. Также были выявлены причины, препятствующие формированию кадрового резерва, которые зависят от многих факторов, в том числе и от личных качеств должностных лиц, работающих в органах местного самоуправления [21].

Социологические исследования по проблематике подготовки кадров государственных и муниципальных служащих проводятся по инициативе РАНХиГС при Президенте Российской Федерации ${ }^{5}$. С 2017 г. АНО «Россия - страна возможностей» проводится Всероссийский конкурс управленцев «Лидеры России». В субъектах Российской Федерации аналогичные проекты осуществляются для привлечения высокопрофессионального поколения управленцев в органы региональной власти и местного самоу-

${ }^{5}$ Аналитические обзоры Института государственной службы и управления Российской академии народного хозяйства и государственной службы при Президенте Российской Федерации». № 3 (2015). М.: РАНХиГС при Президенте Российской Федерации. 2015. 58 с. 
правления в целях обеспечения механизма карьерного роста государственных служащих. Однако, несмотря на видимые успехи, на уровне муниципальных районов эта задача в полной мере еще не решена. От правильной постановки работы с резервом управленческих кадров зависит, какие специалисты придут в низовые звенья системы органов публичной власти.

Эффективное использование профессиональных кадров муниципальных служащих вообще и кадрового резерва в частности находится в предметном поле региональной экономики. Основными критериями для оценки уровня подготовленности лиц, которые намерены связать свою карьеру с государственной и муниципальной службой, являются профессионализм и компетентность. Е. Н. Фурман рекомендует применительно к данному аспекту понимать компетентность как «единство знаний, стремлений, способностей, навыков, личностных и профессиональных качеств резервиста, необходимых для качественного и эффективного исполнения обязанностей в рамках должностного функционала» [17, с. 34].

Сложность формирования кадрового резерва для работы на муниципальном уровне в определенной мере обусловлена незавершённостью разрабатываемых вопросов организационно-методологического характера. В частности, недостаточно проработаны механизмы управления преемственностью руководящего звена муниципального района. Существуют противоречия между объективной потребностью в привлечении высококвалифицированных специалистов в систему муниципального управления и применяемой технологией их отбора на основе компетентностного подхода. Развитие дистанционного обучения и интернет-технологий сопровождается разнообразием программ и расширением форм подготовки и переподготовки слушателей, видов контроля (текущего, промежуточного, итогового) полученных знаний. Данные тенденции, как полагает И. А. Ашмаров, вызывают определенные дискуссии, поскольку живое общение с преподавателями в аудитории заменяется самостоятельной работой, самообучением и самообразованием, а итоги усвоения материала проверяются в процессе тестирования. Образование предполагает развитие нравственных качеств личности [2]. Требованием времени является привитие слушателям понимания категорий этики и морали, необходимости следования в своей работе этическим нормам поведения и культуры общения в работе с персоналом и гражданами. Однако повышение конкуренции на занятие должностей муниципальных служащих объективно способствует достижению устойчивости и результативности всей системы обучения, переобучения и повышения квалификации кадров государственных и муниципальных служащих.

Сам процесс создания кадрового резерва рассматривается нами как последовательность стадий (этапов), включающих выявление, отбор, оценку и подготовку слушателей (будущих муниципальных служащих) в целях оперативного замещения должностей в органах местного самоуправления. Он может осуществляться наиболее эффективно на базе компетентностного подхода, позволяющего обеспечить воспроизводство стабильного, высокопрофессионального руководящего звена местного самоуправления. Одним из путей отражения конкретных компетенций, используемых при отборе претендентов в резерв управленческих кадров, является построение модели компетенций с учетом достижения согласованности требований всеми заинтересованными сторонами: органами государственного (федерального и регионального) управления, предпринимательским сообществом, населением. Исследователи С. Е. Мартынова и О. Г. Масленникова предлагают «сервисную» модель компетенций муниципального служащего, построенную на использовании российского опыта. Эта модель базируется на результатах социологических исследований, в которых отражаются оценки и ожидания всех заинтересованных сторон: как руководителей муниципальных служб, так и претендентов на должности муниципальных служащих [23]. На наш взгляд, данную разработку можно применять при формировании учебных планов для названных категорий обучающихся.

Систему методологически и методически обеспеченных средств (методов), последовательно и целенаправленно применяемых в практике решения проблем кадрового обеспечения на муниципальном уровне управления, следует рассматривать как социальную технологию. Применительно к муниципальным районам технология формирования резерва муниципальных служащих должна обладать способами верификации методологических подходов, комплексностью технологических процедур, системностью их реализации в отношении объектов воздействия (кандидатов в резерв), специально подготовленными субъектами воздействия (например, руководителями и специалистами кадровых подразделений). Сущность этой 
технологии можно определить как комплексный системно-организованный процесс выявления, оценки, отбора кадров на основе модели компетенций, осуществляемый руководителями и работниками кадровых подразделений в целях своевременного удовлетворения потребностей органов местного самоуправления в квалифицированных специалистах.

Информационной основой для принятия решений о создании резерва кадров муниципальных служащих могут стать периодически проводимые социологические обследования по специально разработанным программам. Такие исследования практиковались в 2016-2018 гг. в ряде субъектов ЦФО, включая Курскую область. По результатам этих исследований были выявлены высокий средний возраст сотрудников, отражающий слабый приток молодых специалистов в местные органы власти; несоответствие образовательного уровня муниципальных служащих требованиям современной системы управления [17]. Все вышеперечисленное снижает совокупную способность данных категорий работников к продуктивному труду и требует принятия мер для привлечения в резерв управленческих кадров представителей местного сообщества, удовлетворяющих требованиям системы современного муниципального управления.

В связи с этим все большее значение приобретает социальная база кадрового резерва муниципальных служащих, которая выступает источником информации на уровне муниципальных районов. По результатам выполненного исследования нами установлено, что в данном качестве целесообразно рассматривать «совокупность лиц, проживающих на территории района или аффилированных с ним, имеющих возможность влиять на жизнедеятельность местного сообщества и способных занять руководящие должности в органах местного самоуправления в настоящий момент или после определенной переподготовки» [18, с. 520]. Развитость социальной базы определяется тем, насколько местное сообщество осознает свою общность, единство интересов, целей, для достижения которых оно способно делегировать компетентных специалистов в руководящее звено муниципального района.

Согласно рекомендации кандидата экономических наук В. А. Грищук при переходе на качественно более высокий уровень работы муниципальных служб необходимо использовать как системный, так и институциональный подходы. Оба названных подхода рекомендуется применять к обоснованию не только возможных форм подготовки специалистов, но также вопросов формирования, оценки и эффективного использования резерва кадров для работы в муниципальных органах управления. «Основой кадровой работы являются традиции, система правил, процедур, комплекс мероприятий, связанных с подбором и расстановкой кадров, их подготовкой и переподготовкой, мотивацией и продвижением по карьерной лестнице и т. д.» [5, с. 9].

Востребованность такого понимания проблемы продиктована многокомпонентным характером политики формирования кадрового резерва, ее неразрывной связью с кадровой политикой государства. С позиций системного подхода предпочтительно анализировать особенности местного самоуправления как особый элемент государственного устройства и одновременно как относительно автономное системное образование. Институциональный подход даёт возможность рассматривать формирование резерва кадров как совокупность формально-юридических норм, регулирующих отношения и организацию работы в структуре муниципальной службы.

\section{Заключение}

Вопросы повышения эффективности работы кадрового потенциала муниципальных образований являются в высокой степени актуальными. Это обусловлено целым рядом сохраняющихся в пространственном развитии России проблем, в первую очередь - необходимостью реализации инвестиционного потенциала и повышения конкурентоспособности периферийных территорий субъектов Российской Федерации. Для того чтобы закрепить и последовательно развивать наметившиеся позитивные тенденции в работе муниципальных служб, нужно наладить продуктивную работу по воспитанию молодой смены для занятия в будущем должностей муниципальных служащих и своевременно принимать меры по недопущению текучести кадров. В этих целях необходимо проведение сбалансированной государственной политики регионального развития, в составе которой выделяются два уровня: региональная политика на уровне субъекта Российской Федерации и на уровне муниципальных образований. В структуре внутрирегиональной политики одним из компонентов является эффективная кадровая политика. Ее рекомендуемые составные части: обучение, переобучение и повышение квалификации персонала; создание возможностей для применения организационных и управленческих инноваций; обеспечение резерва управленческих кадров необходи- 
мого уровня квалификации и соответствующих компетенций; создание надежных коммуникаций и средств информационного обеспечения как системы интеллектуальной поддержки при принятии решений - банка информации о состоянии кадровой работы в регионе и муниципальных образованиях; обеспечение возможностей для карьерного роста и формирование системы материального и морального стимулирования муниципальных служащих в согласовании с занимаемой должностью и уровнем подготовки, а также с учетом мнений и пожеланий жителей муниципальных образований.

В работе с муниципальным кадровым резервом сохраняются определенные проблемы. Во-первых, имеет место формальный подход, который остается превалирующим в работе с резервом управленческих кадров и не предполагает оценивание уровня специальной подготовки. Степень овладения претендентами на занятие должностей муниципальных служащих соответствующими компетенциями, как правило, не рассматривается. Во-вторых, отстает от требований времени состояние нормативной правовой базы, которая регулирует данную сферу деятельности и не предполагает карьерных «социальных лифтов» для резервистов, прошедших обучение в системе подготовки управленческих кадров. Вследствие несовершенства действующих документов и инструкций, даже в случаях успешного преодоления конкурсных испытаний, претенденту не предоставляются гарантии по замещению должности муниципального служащего (руководителя подразделения) в органах местного самоуправления.

Одним из приемлемых путей для решения проблемы недостатка профессионально подготовленных специалистов для замещения руководящих должностей муниципальной службы

\section{Библиографический список}

1. Ашмаров И. А. Ответственность и честность государственных и муниципальных служащих как неформальные экономические институты // Регион: государственное и муниципальное управление. 2019. № 2 (18). С. 1-21.

2. Ашмаров И. А. Подготовка, переподготовка и повышение квалификации муниципальных служащих как залог качества и эффективности муниципального управления // Вестник Воронежского института экономики и социального управления. 2019. № 3. С. 4-8.

3. Бухвальд Е. М., Ворошилов Н. В. Актуальные вопросы развития муниципальных образований и реформирования института местного самоуправ- является, на наш взгляд, создание системы формирования муниципального резерва управленческих кадров, в соответствии с которой требования к номинальным претендентам дифференцируются в соответствии с проектируемой номенклатурой должностей. Такие возможности создаются через разработку социальной технологии, включающей оценку кандидатов, основанную на компетентностном подходе. При этом для каждой группы должностей целесообразно разрабатывать адекватные функциональным обязанностям модели компетенций.

В изучении конкретных экономических и социальных проблем, характерных для муниципального уровня, целесообразно применять не только официальные статистические материалы, но и прикладные методы социологических исследований, различные технологии и процедуры обработки и анализа эмпирических данных. В центре внимания высшего менеджмента территорий должно быть изучение и применение передового отечественного и зарубежного опыта, воспитательная и разъяснительная работа с различными возрастными категориями населения. Рекомендуемые технологии оценки и отбора претендентов на замещение руководящих должностей призваны способствовать дальнейшей профессионализации и повышению уровня компетентности муниципальных служащих. Сформированный на основе компетентностного подхода кадровый резерв станет основой для привлечения в органы местного самоуправления высокопрофессиональных руководителей и специалистов.

\section{Конфликт интересов}

Авторы декларируют отсутствие явных и потенциальных конфликтов интересов, связанных с публикацией настоящей статьи.

ления // Экономические и социальные перемены : факты, тенденции, прогноз. 2018. Т. 11, № 1. C. 132-147. DOI: 10.15838/esc.2018.1.55.9.

4. Гранберг А. Г. Основы региональной экономики. М. : ГУ ВШЭ, 2000. 495 с.

5. Грищук В. А. Влияние кадровой политики на стратегическое управление муниципальной службой // Общество, экономика, управление. 2019. Т. 4, № 2. С. 7-15.

6. Дворядкина Е. Б., Белоусова Е. А. Муниципальные районы и сельские поселения : экономические и правовые аспекты // Вестник ЮУрГУ. Серия «Экономика и менеджмент». 2018. Т. 12, № 1. С. 42-50. DOI: $10.14529 / \mathrm{em} 180106$. 
7. Волкова А. Г., Трещевская Н. Ю. Формы и методы регулирования социально-экономического развития регионов: практика и перспективы развития // Вестник Воронежского государственного университета. Серия: Экономика и управление. 2019. № 3. C. 59-64.

8. Ворошилов Н. В. Региональная политика по развитию муниципальных образований: оценка эффективности и особенности реализации в современных условиях // Экономические и социальные перемены : факты, тенденции, прогноз. 2019. T. 12, № 5. C. 58-75. DOI: 10.15838/esc.2019.5.65.4.

9. Клеман-Питио Э. Долгосрочная стратегия развития российской экономики : выбор в пользу прагматизма // Научные труды: Ин-т народнохозяйственного прогнозирования РАН / гл. ред. А. Г. Коровкин. М. : МАКС-Пресс, 2014. С. 8-38.

10. Молчанов И. Н., Молчанова Н. П. Пространственное развитие России : управление сельскими территориями // Аграрный вестник Урала. 2020. № 2 (193). C. 78-88. DOI: 10.32417/1997-4868-2020-193-278-88.

11. Попов А. В.Изменение требований российской экономики к трудовому потенциалу работников в условиях современных вызовов // Экономика труда. 2020. T. 7, № 8. C. 643-658. DOI: 10.18334/et.7.8.110733.

12. Региональные аспекты долгосрочной экономической политики : научный доклад. М. : Международные отношения, 2018. 69 с.

13. Сабитова Н. М. Финансовые риски и финансовая деятельность публично-правовых образований // Финансы и кредит. 2018. Т. 24, № 3. С. 565-578.

14. Ускова Т. В. Проблемы и перспективы социально-экономического развития российских территорий // Проблемы развития территории. 2018. № 2 (42). C. 1-15. DOI: 10.15838/tdi.2018.2.42.1.

15. Ускова Т. В. О потенциале развития российских территорий // Проблемы развития территории. 2018. № 5 (97). C. 7-17. DOI: 10.15838/ptd.2018.5.97.1.

16. Ускова Т. В., Ворошилов Н. В. Региональная политика территориального развития : моногра- фия. Вологда : ИСЭРТ РАН, 2015. 156 с. [Проблемы эффективности государственного управления].

17. Фурман E. Н. Компетентность представителей управленческого резерва субъекта РФ : к определению понятия // Теория и практика общественного развития. 2018. № 11 (129). С. 32-35.

18. Фурман Е. Н., Молчанова Н. П. Муниципальный уровень управления : особенности работы с кадрами // Глобальные проблемы модернизации национальной экономики: материалы IX Междунар. науч.-практ. конф. 13 апреля 2020 г. / отв. ред. А. А. Бурмистрова [и др.] ; Мин-во науки и высшего образования РФ, Тамб. гос. ун-т им. Г. Р. Державина». Тамбов : Державинский, 2020. С. 513-524.

19. Aedo C., Hentschel J., Luque J., Moreno M. From Occupations to Embedded Skills : A Cross-Country Comparison. Policy Research Working Paper No. WPS 6560. Washington, D.C. : World Bank, 2013. 25 p.

20. Autor D. H., Levy F., Murnane R. J. The Skill Content of Recent Technological Change : An Empirical Exploration // The Quarterly Journal of Economics. 2003. № 118 (4). P. 1279-1333.

21. Sergei A. Vorontsov, Alexander V. Ponedelkov. Staffing innovations in the municipal territory // CBU international conference on innovations in science and education, March 21-23, 2018. P. 853-859.

22. Dewey John. Apres le liberalisme? Ses impasses, son avenir, 1935 (Дьюи Д. После либерализма? Его тупики, его будущее) / пер. G. Garreta Climats / Flammarion, 2014. 173 c.

23. Martynova S. E. and Maslennikova O. G. The "Service" model of the competences of the municipal employee as the basis of vocational training: Russian experience / Procedia - Social and Behavioral Sciences 174. 2015. P. 2716-2720.

24. Nagimov A. R., Akhmetshin E. M., Slanov V. P., Shpakova R. N., Solomonov M. P., Ilyaschenko D. P. Foresight Technologies in the Formation of a Sustainable Regional Development Strategy // European Research Studies Journal. 2018. Vol. 21, no. 2. P. 741-752.

Молчанова Наталья Петровна, доктор экономических наук, профессор Департамента общественных финансов финансового факультета, Финансовый университет при Правительстве Российской Федерации, Москва, Российская Федерация

E-mail: NPMolchanova@fa.ru

ORCID: 0000-0002-3019-0672

Поступила в редакцию 19.062020

Подписана в печать 10.09.2020 


\title{
Problems of forming a staff reserve for municipal employees
}

\author{
E. N. Furman ${ }^{1}$, N. P. Molchanova ${ }^{2} \bowtie$
}

${ }^{1}$ Kursk Academy of State and Municipal Service, Kursk, Russian Federation

${ }^{2}$ Financial University under the Government of the Russian Federation, Moscow, Russian Federation

Cite as: Furman, E. N., Molchanova, N. P. Problems of forming a staff reserve for municipal employees. Proceedings of Voronezh State University. Series: Economics and Management. 3, 89-100. (In Russ., abstract in Eng.). DOI: 10.17308/econ.2020.3/3108

Introduction. The tasks developed within the framework of the ongoing intraregional policy are very diverse and are aimed at improving the life of the population and the development of municipalities. The success of their implementation largely depends on the quantitative and qualitative characteristics of the available factors of production. The key role belongs to human resources, namely: the presence of a contingent of municipal employees with the necessary competencies and qualifications. In this regard, it is necessary to prepare tools for ranking the quality of labour activity of municipal employees, adequate to the specific conditions of spatial development. The methodology for assessing labour contribution should include incentives to improve the performance of management activities that meet the requirements of the modern period of formation of the information economy.

Revealing the relationship between the qualifications and competencies of working specialists in the administrations of municipalities and the socio-economic results of the functioning of the peripheral territories of the constituent entities of the Russian Federation.

Methods. In the course of the study, methods of induction and deduction, comparative and situational analysis, expert assessments, statistical methods of processing and analysing information, and the results of sociological surveys were used.

Results and discussion. An analysis of the work of municipal administrations based on research materials for the Central Federal District and the Kursk Region using official statistical information and materials of sociological observations has been carried out. Factors positively and negatively affecting the performance of local government bodies have been established. Features of work and selection of municipal employees, revealed significant shortcomings in their training and preparation for practical activities, studied. The issue of creating a qualitatively new system for the training of municipal employees with the knowledge and competencies required to work in the digitalization environment is relevant. It is necessary to actively apply various forms of training and professional development of specialists of local administrations, to take into account the opinions of residents of urban and rural settlements. It is advisable to recommend the tools of the program-oriented approach and expert assessments for use when justifying the scale of training a contingent of reservists to replenish the staff of municipal employees.

Conclusion. The effectiveness of the activities of public authorities at the lower level is largely determined by the active position of the heads of municipal districts and employees of the apparatus of municipalities. The creation of a personnel reserve of municipal employees has a positive impact on the results of the work of the administrations of municipalities and the socio-economic situation of the territories. To achieve the targets in terms of the planned rates of economic and social development, it is necessary to activate various forms of work with specialists from the administrations of urban and rural settlements. Recommendations are formulated for the formation of a pool of municipal employees, based on the use of social technologies and modelling of competencies for the purpose of high-quality training of specialists for work in leadership positions in local authorities.

Key words: intra-regional policy, local self-government, features of the municipal economy, financial resources of municipalities.

\section{Conflict of Interest}

The author declares that there are no obvious or potential conflicts of indifference related to the publication of this article.

\section{References}

1. Ashmarov, I. A. (2019) Otvetstvennost' i chestnost' gosudarstvennyh i municipal'nyh sluzhashhih kak neformal'nye jekonomicheskie instituty [Responsibility and honesty of state and municipal employees 
as informal economic institutions]. Region: gosudarstvennoe i municipal'noe upravlenie [Region: state and municipal management]. 2 (18), 1-21. (In Russ.)

2. Ashmarov, I. A. (2019) Podgotovka, perepodgotovka i povyshenie kvalifikacii municipal'nyh sluzhashhih kak zalog kachestva i jeffektivnosti municipal'nogo upravlenija [Training, retraining and advanced training of municipal employees as a guarantee of the quality and efficiency of municipal management]. Vestnik Voronezhskogo instituta jekonomiki i social'nogo upravlenija [Bulletin of the Voronezh Institute of Economics and Social Management]. 3, 4-8. (In Russ.)

3. Bukhvald, E. M. \& Voroshilov, N. V. (2018) Aktual'nye voprosy razvitija municipal'nyh obrazovanij i reformirovanija instituta mestnogo samoupravlenija [Topical issues of development of municipalities and reforming the institution of local self-government]. Jekonomicheskie i social'nye peremeny: fakty, tendencii, prognoz. [Economic and social changes: facts, trends, forecast]. 11 (1), 132 -147.DOI: 10.15838/esc.2018.1.55.9 (In Russ.)

4. Granberg, A. G. (2000) Osnovy regional'noj jekonomiki. [Fundamentals of Regional Economics]. Moscow, GU HSE Publ. (In Russ.)

5. Grischuk, V. A. (2019) Vlijanie kadrovoj politiki na strategicheskoe upravlenie municipal'noj sluzhboj. [The influence of personnel policy on the strategic management of the municipal service]. Obshhestvo, jekonomika, upravlenie. [Society, Economics, Management]. 4(2), 7-15. (In Russ.)

6. Dvoryadkina, E. B. \& Belousova E. A. (2018) Municipal'nye rajony i sel'skie poselenija: jekonomicheskie i pravovye aspekty [Municipal districts and rural settlements: economic and legal aspects]. Vestnik JuUrGU. Serija "Jekonomika i menedzhment" [Bulletin of SUSU. Series "Economics and Management”]. 12 (1), 42-50. DOI: 10.14529/em 180106 (In Russ.)

7. Volkova, A. G. \& Treshchevskaya, N. Yu. (2019) Formy i metody regulirovanija social'no-jekonomicheskogo razvitija regionov: praktika i perspektivy razvitija [Forms and methods of regulation of socio-economic development of regions: practice and development prospects] Vestnik Voronezhskogo gosudarstvennogo universiteta. Serija: Jekonomika i upravlenie [Bulletin of the Voronezh State University. Series: Economics and Management]. 3, 59-64. (In Russ.)

8. Voroshilov, N. V. (2019) Regional'naja politika po razvitiju municipal'nyh obrazovanij: ocenka jeffektivnosti i osobennosti realizacii v sovremennyh uslovijah [Regional policy for the development of municipalities: assessment of efficiency and implementation features in modern conditions]. Jekonomicheskie i social'nye peremeny: fakty, tendencii, prognoz [Economic and social changes: facts, trends, forecast]. 12 (5), 58-75. DOI: 10.15838/esc.2019.5.65.4 (In Russ.)

9. Clement-Pitio, E. (2014) Dolgosrochnaja strategija razvitija rossijskoj jekonomiki: vybor v pol'zu pragmatizma [Long-term strategy for the development of the Russian economy: a choice in favor of pragmatism]. In Korovkin A. G. (ed.) Nauchnye trudy: In-t narodnohozjajstvennogo prognozirovanija $R A N$ [Scientific works: Institute of National Economic Forecasting RAS]. Moscow, MAKS-Press, 8-38. (In Russ.)

10. Molchanov, I. N. \& Molchanova, N. P. (2020) Prostranstvennoe razvitie Rossii: upravlenie sel'skimi territorijami [Spatial development of Russia: management of rural areas]. Agrarnyj vestnik Urala [Agrarian Bulletin of the Urals]. 2 (193), 78-88. DOI: 10.32417 / 1997-4868-2020-193-2-78-88 (In Russ.)

11. Popov, A. V. (2020) Izmenenie trebovanij rossijskoj jekonomiki k trudovomu potencialu rabotnikov v uslovijah sovremennyh vyzovov [Changing the requirements of the Russian economy to the labor potential of workers in the context of modern challenges]. Jekonomika truda [Labor Economics]. 7 (8), 643-658. DOI: 10.18334/et.7.8.110733. (In Russ.)

12. Mikheeva, N. N. Suvorov, A. V., Shirov, A. A., Shokin, I. N. Yankov, K. V., Potapenko, V. V. \& Sapova N. N. (2018) Regional'nye aspekty dolgosrochnoj jekonomicheskoj politiki [Regional aspects of long-term economic policy]. Moscow, International Relations Publishing House. (In Russ.)

13. Sabitova, N. M. (2018) Finansovye riski i finansovaja dejatel'nost' publichno-pravovyh obrazovanij [Financial risks and financial activity of public legal entities]. [Finance and credit]. 24, 3, 565-578. (In Russ.)

14. Uskova, T. V. (2018) Problemy i perspektivy social'no-jekonomicheskogo razvitija rossijskih territorij [Problems and prospects of socio-economic development of Russian territories]. Problemy razvitija territorii [Problems of territory development]. 2 (42), 1-15. DOI: $10.15838 /$ tdi.2018.2.42.1

15. Uskova, T. V. (2018) O potenciale razvitija rossijskih territorij [On the development potential of Russian territories]. Problemy razvitija territorii [Problems of territory development]. 5 (97), 7-17. DOI: 10.15838/ptd.2018.5.97.1 (In Russ.)

16. Uskova, T. V. \& Voroshilov, N.V. (2015) Regional'naja politika territorial'nogo razvitija [Regional policy of territorial development]. Vologda, ISERT RAN. (In Russ.)

17. Furman, E. N. (2018) Kompetentnost' predstavitelej upravlencheskogo rezerva subjekta RF: k opredeleniju ponjatija [Competence of representatives of the administrative reserve of a constituent entity of the Russian Federation: towards the definition of the concept]. Teorija i praktika obshhestvennogo razvitija [Theory and practice of social development]. 11 (129). 32-35. (In Russ.)

18. Furman, E. N. \& Molchanova, N. P. (2020) Municipal'nyj uroven' upravlenija: osobennosti raboty s kadrami [Municipal level of management: features of work with personnel]. In Burmistrova A. A. et al. (eds.) Global'nye problemy modernizacii nacional'noj jekono- 
miki: materialy IX Mezhdunarodnoj nauchno-prakticheskoj konferencii [Global problems of modernization of the national economy: materials of the IX International scientific and practical conference], 13 April 2020, Tambov, Derzhavinsky Publ., 513-524. (In Russ.)

19. Aedo, C., Hentschel, J., Luque, J. \& Moreno, M. (2013) From Occupations to Embedded Skills: A Cross-Country Comparison. Policy Research Working Paper No. WPS 6560. - Washington, D.C., World Bank.

20. Autor, D. H., Levy, F., \& Murnane, R. J. (2003)

The Skill Content of Recent Technological Change: An Empirical Exploration. The Quarterly Journal of Economics. 118(4), 1279-1333.

21. Vorontsov, S A. \& Ponedelkov, A. V. (2018) [Staffing innovations in the municipal territory]. In [CBU international conference on innovations in science and education], March 21-23, 853-859. (In Russ.)

22. Dewey, J. (1935) Liberalism and Social Action. New York, G.P. Putnam.

23. Martynova, S. E. \& Maslennikova, O. G. (2015) [The "Service" model of the competences of the municipal employee as the basis of vocational training: Russian experience]. Procedia - Social and Behavioral Sciences. 174, 2716-2720. (In Russ.)

24. Nagimov, A. R., Akhmetshin E. M., Slanov V. P., Shpakova R. N., Solomonov M. P. \& Ilyaschenko D. P. (2018) [Foresight Technologies in the Formation of a Sustainable Regional Development Strategy]. [European Research Studies Journal]. 21 (2), 741-752. (In Russ.)

Natalia P. Molchanova, Doctor of Economics, Professor, Department of Public Finance, Faculty of Finance, Financial University under the Government of the Russian Federation, Moscow, Russian Federation

E-mail: NPMolchanova@fa.ru

ORCID: 0000-0002-3019-0672

Received 19.062020

Accepted 10.09.2020 